SAKAI SAMBAYAN — Jurnal Pengabdian kepada Masyarakat

\title{
Peningkatan Partisipasi Masayarakat pada Studi Pemetaan Partisipatif dalam Pembuatan Jalur Evakuasi Bencana Tsunami di Desa Wisata Pagar Jaya
}

\author{
Rahmat C. Wibowo, Karyanto, Ahmad Zaenudin, Muh. Sarkowi \\ Jurusan Teknik Geofisika, Fakultas Teknik \\ Universitas Lampung \\ Penulis Korespodensi: rahmat.caturwibowo@eng.unila.ac.id
}

\begin{abstract}
Abstrak
Desa wisata Pagar Jaya memiliki beberapa obyek geowisata yang sangat menarik untuk dikunjungi seperti: Dinding Dasit, Pantai T. Indah, Pantai T. Hantu, dan Batu Wayang. Semua obyek geowisata tersebut berada di area pesisir dan sangat rentan terhadap ancaman bencana tsunami. Nilai penting dari proses partisipatif dalam kajian risiko bencana adalah mewadahi masyarakat dalam mengambil keputusan dan merumuskan tindakan prioritas pengurangan risiko bencana. Tujuan dari pengabdian ini adalah: memetakan kondisi eksisting obyek geowisata Dinding Dasit, Teluk Indah, Teluk Hantu, dan Batu Wayang berbasis geospasial, mengedukasi masyarakat akan prinsip-prinsip mitigasi bencana tsunami, dan mengintegrasikan data geospasial dan nonspasial dari kelompok masyarakat dalam pembuatan jalur evakuasi bencana tsunami di Desa Wisata Pagar Jaya. Kelompok masyarakat yang tergabung dalam Kelompok Sadar Wisata (Pokdarwis) Desa Wisata Pagar Jaya merupakan subjek utama dalam proses pemetaan partisipatif. Proses pemetaan melalui tahap Focus Group Discussion dan in-depth interview berkaitan dengan risiko bencana dan jalur evakuasi. Sistem Informasi Geografis kemudian mentransformasikan hasil pemetaan partsipatif dalam bentuk digital. Hasil dari penelitian ini adalah peta partisipatif jalur evakuasi untuk bencana tsunami di Desa Pagar Jaya yang secara geografis berada di pesisir selatan Pulau Sumatera.
\end{abstract}

Kata kunci: pagar jaya, geowisata, mitigasi bencana, tsunami, pemetaan

\section{Pendahuluan}

Penetapan daerah geowisata didasarkan pada 3 elemen utama (Dowling dan Newsome, 2006), yaitu (1) bentuk geologi (lansekap, landform, sedimen, batuan, dan fosil) sebagai daya Tarik utama; (2) proses pembentukan geologi (mencakup aktivitas tektonik, erosi, deposisi, dan lain-lain) dengan produk berupa pegunungan, aliran lava, glacier, air terjun, lembah sungai, delta; dan (3) pariwisata yang menggabungkan daya tarik geologi sebagai atraksi utama, didukung oleh akomodasi, aktivitas wisata, serta pengelolaan (pengelolaan Kawasan, pengelolaan pengunjung, desain kawasan, dan lain-lain). Tujuan pengelolaannya adalah membangun dan mengembangkan ekonomi masyarakat setempat dengan berdasarkan perlindungan atas ketiga keragaman yang terdapat pada kawasan tersebut (Sinarta, 2013).

Obyek geowisata di Desa Pagar Jaya seperti: Dinding Dasit, Pantai T. Indah, Pantai T. Hantu, dan Batu Wayang berada di area pesisir dan sangat rentan terhadap ancaman bencana tsunami. Namun, potensi ancaman bencana tsunami ini belum disadari sepenuhnya dikarenakan masyarakat setempat masih awam. Berdasarkan hal tersebut, peran serta akademisi dituntut untuk mengedukasi masyarakat, agar masyarakat memiliki kemampuan, kapasistas, dan kesiapan terhadap bencana tsunami yang sangat berpotensi disekitar mereka (Karyanto, dkk., 2018).

Berbagai pendekatan ditempuh untuk dapat menanggulangi bencana, belum dapat menunjukkan pengurangan dampak secara signifikan. Salah satu keterbatasan dalam aplikasi metode pengurangan risiko bencana adalah fokus penyelesaian yang hanya berorientasi pada penyelamatan korban bencana, bukan pada tataran pencegahan. Korban bencana pada umumnya digambarkan sebagai komunitas marginal yang belum mampu menghadapi bencana yang berpotensi merugikan (Gaillard, 2010). Lebih lanjut, Gaillard, dkk. (2008) menggambarkan komunitas marginal tersebut secara geografis tersebar di kawasan rawan bencana, secara sosial tergabung dalam kaum minoritas, secara ekonomis tergolong kelompok masyarakat ekonomi ke bawah, dan secara politis termasuk kelompok 
masyarakat yang tidak memiliki hak suara yang kuat.

Kajian risiko bencana selanjutnya yang berkaitan dengan penilaian dan perencanaan darurat mulai mengintegrasikan peran pemerintah daerah, unsur publik, dan masyarakat setempat. Masyarakat lokal yang terdampak bencana ikut terlibat dalam proses pengumpulan data, analisis risiko bencana, atau merencanakan penanganan darurat. Metode yang mengakomodasi peran masyarakat untuk pengurangan risiko bencana kemudian dikenal sebagai Pengurangan Risiko Bencana Berbasis Komunitas (PRBBK). Salah satu langkah untuk meminimalkan keterbatasan komunikasi antara masyarakat dan pemerintah adalah dengan peningkatan kapasitas melalui pemetaan partisipatif bencana (Spanu, dkk., 2015).

Pemetaan partisipatif sudah dimulai dan dikembangkan sejak tahun 1980. Metode pemetaan berawal dari teknik sederhana dan tradisional memanfaatkan lahan terbuka seperti lapangan sebagai alas gambar. Peta saat itu adalah berupa sketsa yang saat ini berkembang menjadi model tiga dimensi hingga ke ranah sistem online. Manfaat dari pemetaan partisipatif khususnya di bidang kebencanaan sudah dapat dirasakan oleh masyarakat lokal dan dijadikan pedoman di berbagai literatur ilmiah (Piccolella, 2013).

Potensi pengetahuan masyarakat dalam bidang kebencanaan dapat diintegrasikan dengan metode pemetaan partisipatif untuk menghasilkan informasi spasial yang mendukung kapasitas lokal.

Tujuan diadakannya pengabdian ini adalah memberikan pengetahuan kepada kelompok
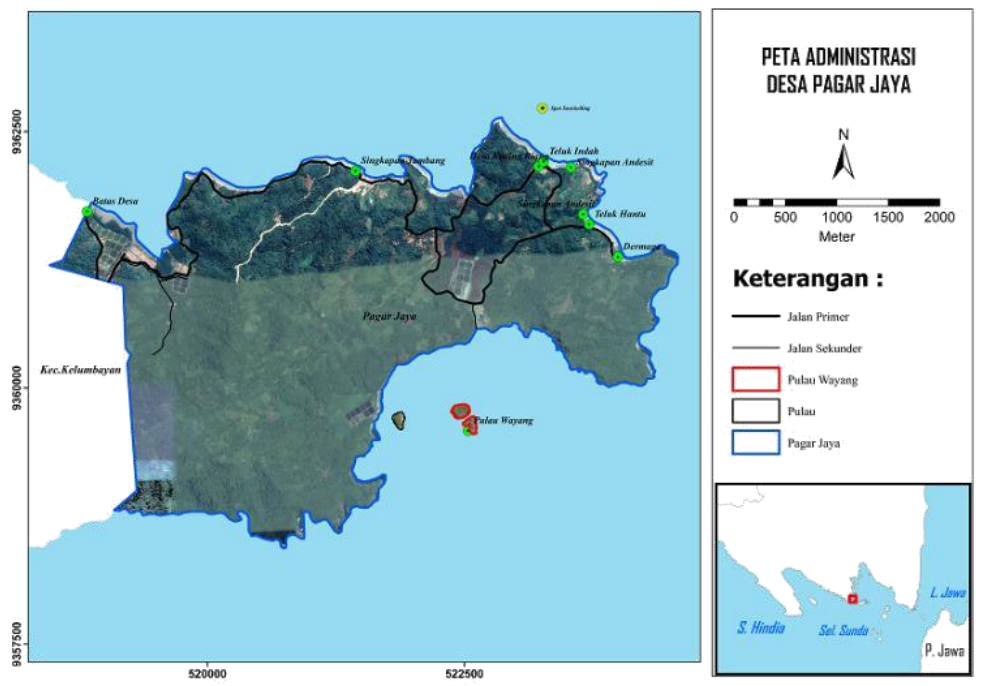

Gambar 1. Peta administrasi Desa Pagar Jaya, Kecamatan Punduh Pidada, Kabupaten Pesawaran masyarakat (Pokdarwis) akan prinsip-prinsip nitigasi bencana tsunami dan pembuatan jalur evakuasinya. Manfaat yang akan diperoleh sesudah diadakannya pengabdian ini adalah:

a. Terpetakannya seluruh bentang alam secara 2D berupa peta luasan Desa Wisata Pagar Jaya, Kecamatan Punduh Pidada.

b. Terpetakannya jalur evakuasi bencana tsunami di Desa Wisata Pagar Jaya, dan

c. Masyarakat mendapatkan pengetahuan tentang potensi bencana alam di daerahnya (khususnya tsunami), berperan aktif dalam pembuatan jalur evakuasi bencana tsunami dan memiliki kemampuan, kesiapan, dan kapasitas dalam menghadapi bencana tsunami.

\section{Metodologi}

A. Lokasi Penelitian

Kajian penyusunan basis data spasial skala desa menggunakan informasi dari pemetaan partisipatif dilaksanakan di Desa Pagar Jaya, Kecamatan Punduh Pidada, Kabupaten Pesawaran (Gambar 1). Desa Pagar Jaya merupakan salah satu dari sebelas desa di Kecamatan Punduh Pidada, Kabupaten Pesawaran. Jumlah penduduk pada Tahun 2018 sebesar 1.265 orang yang terdiri dari 688 penduduk laki-laki dan 577 penduduk perempuan. Mata Pencaharian penduduk terbesar adalah sebagai petani, diikuti nelayan (BPS, 2018). Desa ini terletak kurang lebih 94 kilometer ke arah 
Selatan dari Kota Bandar Lampung. Luas wilayah Desa Pagar Jaya secara keseluruhan adalah $400 \mathrm{Ha}$, dengan potensi desa antara lain di sektor pertanian, perikanan, dan wisata.

\section{B. Data}

Data dalam penelitian ini terdiri dari dua jenis data, yaitu data primer dan data sekunder. Data sekunder yang digunakan meliputi citra satelit Google Earth dengan waktu perekaman citra bulan Juli Tahun 2018 dan data jaringan jalan dan blok bangunan dari layanan Open Street Map. Adapun data primer yang dihasilkan dari kajian ini antara lain, peta tata guna lahan, batas wilayah, infrastruktur dan fasilitas umum desa, serta data elevasi.

\section{Teknik Pemetaan}

Pembuatan peta penggunaan pahan berbasis interpretasi citra penginderaan jauh dapat dilakukan menggunakan dua metode, yaitu intepretasi visual dan klasifikasi dijital. Interpretasi visual biasanya dilakukan pada data penginderaan jauh yang berformat analog/cetakan atau secara dijital melalui digitasi pada layar monitor. Pada proses interpretasi visual, interpreter berusaha mengenali obyek di permukaan bumi dengan mendasarkan pada kunci interpretasi yang terdiri dari rona/warna, bentuk, pola, tekstur, bayangan, ukuran, asosiasi dan situs (Sutanto, 1986). Obyek yang teridentifikasi kemudian di deliniasi batasnya dan akhirnya dihasilkan sebuah peta tematik sebaran obyek hasil identifikasi. Sedangkan pada klasifikasi dijital, proses pengenalan obyek dilakukan secara otomatis oleh komputer. Komputer mengenali obyek hanya berdasarkan pada dua aspek, yaitu atribut spektral/warna dan atribut spasial/tekstur. Oleh karena itu penggunaan klasifikasi dijital hanya terbatas untuk pemetaan penutup lahan atau penggunaan lahan yang mempunyai tekstur spesifik saja.

Teknik interpretasi visual dalam penelitian ini digunakan untuk melakukan pemetaan penggunaan lahan. Sebagai dasar interpretasi, digunakan citra satelit resolusi tinggi terbaru. Hasil peta penggunaan lahan yang diperoleh kemudian divalidasi dan dilengkapi informasinya dari hasil kegiatan pemetaan partisipatif. Pemetaan penggunaan lahan dalam penelitian ini menggunakan skema klasifikasi penggunaan lahan dalam Peraturan Kepala Badan Informasi
Geospasial Nomor 3 Tahun 2016 tentang Spesifikasi Teknis Penyajian Peta Desa.

Teknik pemetaan partisipatif dapat dibedakan menjadi beberapa jenis menurut Cadag and Gaillard (2012). Teknik pemetaan partisipatif tersebut antara lain Ground Mapping, Stone Mapping, Sketch Mapping, Scaled 2D Mapping, WebGIS based Mapping dan GPS Mapping. Adapun teknik pemetaan partisipatif yang digunakan dalam kajian ini adalah teknik Scaled 2D Mapping, yaitu teknik pemetaan partisipatif dimana nara sumber menggambarkan informasi yang diketahui (menggunakan alat tulis dan gambar) ke dalam peta dasar dalam bentuk cetak. Teknik Scaled 2D Mapping lebih dipilih daripada metode pemetaan partisipatif lain dengan pertimbangan: (1) narasumber yang dilibatkan adalah perangkat desa yang sudah cukup familiar dengan peta dan foto meminimalisir distorsi informasi yang dipetakan. Peta dasar yang digunakan adalah citra satelit resolusi rendah yang ditumpang-susunkan dengan peta persil tanah yang dimiliki oleh pemerintah desa. Pada umumnya nara sumber perangkat desa (kepala padukuhan) di masa lalu menggunakan peta persil sebagai dasar untuk mengingat berbagai obyek spasial di wilayah yang ditanganinya, sehingga kombinasi antara citra satelit resolusi rendah dan peta persil dapat memaksimalkan proses ekstraksi berbagai informasi yang diketahui nara sumber, dan memudahkan transfer informasi dari bentuk peta mental (mental map) ke peta fisik (physical map).

Hasil pemetaan partisipatif kemudian diubah menjadi bentuk digital melalui proses scanning peta cetak hasil penggambaran oleh nara sumber, dilanjutkan proses georeferencing peta hasil scan, dijitasi komputer untuk memperoleh data spasial dalam bentuk vektor, dan diakhiri dengan pengisian data atribut. Hasil pemetaan partisipatif kemudian diintegrasikan dengan hasil pemetaan penggunaan lahan yang dilakukan peneliti, sebagai pelengkap informasi hasil pemetaan Penggunaan lahan dan sekaligus menjadi bahan validasi hasil pemetaan penggunaan lahan. Hasil pemetaan yang telah dilakukan kemudian disampaikan kembali kepada nara sumber untuk divalidasi dan dikoreksi apabila ditemukan kesalahan. Produk akhir hasil kegiatan pemetaan kemudian dikompilasi dalam bentuk basis data spasial geodatabase, dan didiseminasikan dalam bentuk peta cetak. 


\section{Hasil dan Pembahasan}

Pemahaman dasar sebuah perencanaan pengurangan risiko bencana adalah tentang apa dan siapa yang berada di kawasan risiko tsunami dengan keberadaan sumberdaya dan potensi lokal untuk mitigasi bencana (Cadag and Gaillard, 2012). Melalui proses pemetaan bahaya hingga risiko tsunami, masyarakat dapat memahami kebutuhan dasar untuk menghadapi kemungkinan datangnya tsunami (Gambar 2). Untuk itu, rencana aksi khususnya di tingkat komunitas menjadi penting dalam upaya mengurangi risiko bencana. Perencanaan ini fokus pada fase kesiapsiagaan dan tanggap darurat bencana yang digambarkan melalui peta jalur dan tempat evakuasi.

Berdasarkan pendekatan yang telah ditempuh, masyarakat secara mandiri dan sadar dapat menentukan strategi bertahan menghadapi bencana. Hal tersebut dapat memberikan pengaruh positif terutama bagi kelompok rentan untuk memahami tingkat kerentanan dan kapasitas lokal di Desa Pagar Jaya. Persepsi ini kemudian menjadi pedoman pengurangan risiko bencana tingkat desa yang selalu dihadapkan pada faktor ekologi dan sosial yang dinamis dan tidak menentu (Cadag and Gaillard, 2012). Implementasi rencana tanggap darurat (Gambar 2) disampaikan melalui dua konsep dasar yaitu : (1) Pengembangan skenario dampak dan kejadian tsunami, dan (2) Sistem peringatan dini partisipatif. Peran penting kelompok sadar wisata (Pokdarwis) di Desa Pagar Jaya menunjukkan besarnya partisipasi komando dalam mengkoordinasikan sistem penanggulangan bencana. Hal ini terwujud dalam sistem peringatan dini yang dikembangkan dari potensi dan kearifan lokal.
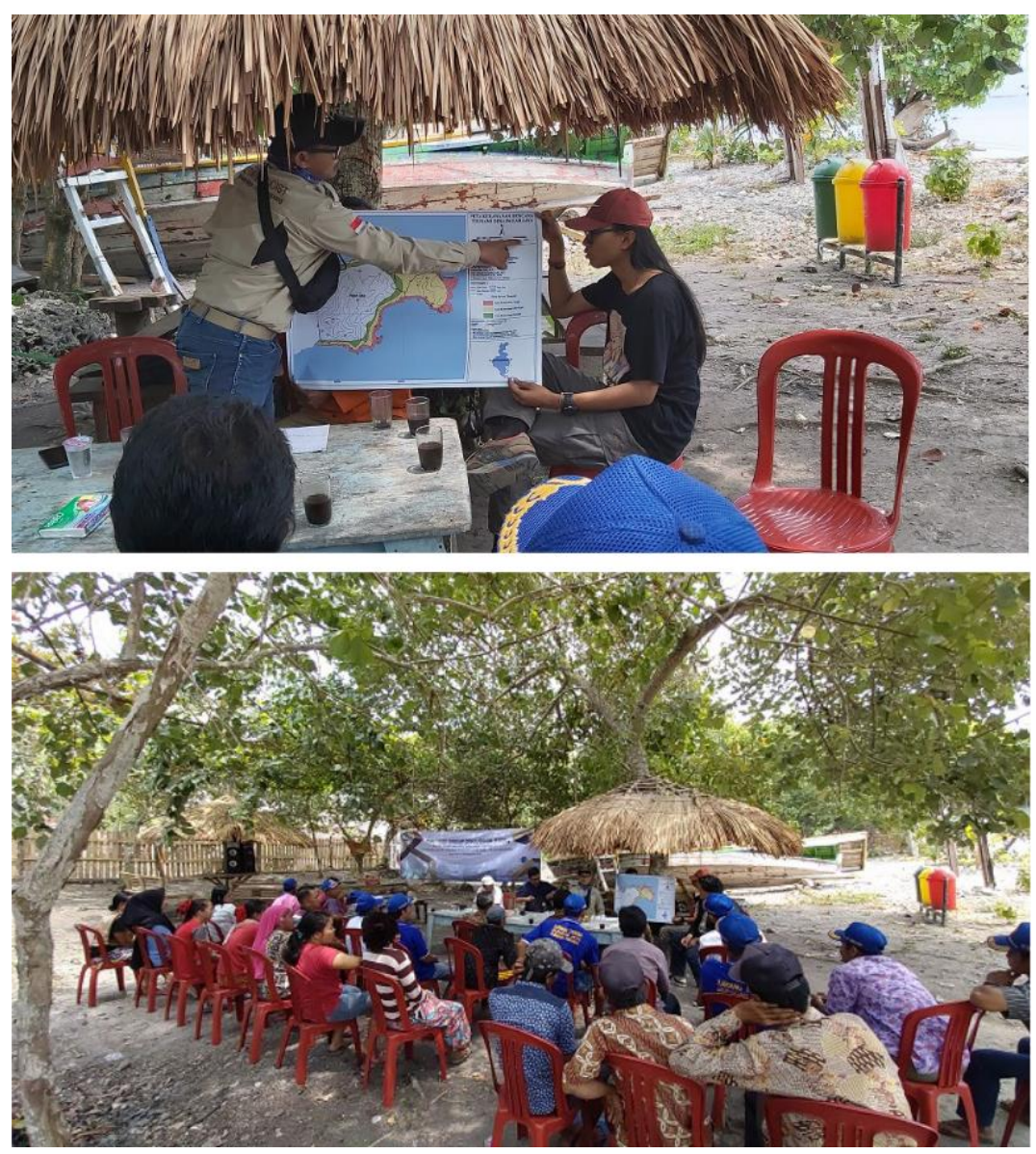

Gambar 2. FGD pemetaan partisipatif kerentanan bencana tsunami

Segala bentuk perencanaan penganggulangan bencana terangkum dalam Rencana Penanggulangan Bencana (RPB) yang merupakan embrio terbentuknya Rencana Aksi
Komunitas (RAK) di tingkat Desa Pagar Jaya. Dokumen RAK mengandung seluruh rencana tindakan yang akan dilakukan masyarakat pada fase sebelum bencana hingga fase tanggap darurat 
bencana. Lebih lanjut, RAK tersebut dapat dijadikan pedoman kesiapsiagaan masyarakat secara mandiri menghadapi bencana tsunami. Hal terpenting di dalam RAK adalah adanya sistem peringatan dini yang disusun oleh masyarakat sendiri dengan melibatkan peran penting dari unsur di dalam kelompok masyarakat serta mengakomodasi kearifan lokal.

Salah satu urgensi unsur pemetaan bencana adalah peta jalur evakuasi. Skema evakuasi direpresentasikan dalam peta jalur dan tempat evakuasi tingkat desa dan didasarkan pada persebaran kelompok rentan, ketersediaan pemilik kendaraan modil dan truk, ketersediaan lapangan atau bangunan ramah bencana, dan ketersediaan akses berupa jalan yang aman dan lebih tinggi. Fasilitas umum seperti sekolah, pasar, dan lapangan balai desa diidentifikasi sebagai tempat evakuasi sementara dan akhir. Berdasarkan pertimbangan tersebut, masyarakat Desa Pagar Jaya menentukan beberapa titik evakuasi sementara sebagai wadah pertama bagi masyarakat untuk menyelamatkan diri. Dasar utama pemilihan titik evakuasi sementara ini adalah persebaran kepadatan penduduk dan kelompok rentan.

Peran SIG pada penelitian ini hanya fokus pada penyajian dan visualisasi data hasil FGD dan in depth interview oleh masyarakat. Pemetaan partisipatif yang berbasis SIG diadopsi dengan cukup baik untuk menilai kebutuhan dan menganalisis permasalahan, persepsi dan potensi lokal, serta untuk mengidentifikasi strategi bertahan (coping strategies) dari masyarakat untuk menghadapi bencana (Dekens, 2007). Namun, masyarakat Desa Pagar Jaya tidak memiliki kemampuan memadai untuk mengeoperasikan perangkat komputer. Hal ini dapat diatasi dengan melibatkan peran akademisi untuk proses pengolahan dan analisis data partisipatif ke dalam SIG. Secara umum, peta partisipatif kurang representatif dan ilmiah jika akan dijadikan dasar analisis dan pengambilan keputusan. Untuk itu, integrasi SIG dalam bidang kebencanaan melalui pemetaan partisipatif jalur evakuasi merupakan solusi bagi pemerintah dan ilmuwan untuk menelaah pengurangan risiko bencana. Hal ini relevan dengan pemetaan risiko bencana menggunakan SIG dalam konteks pembangunan. Akan tetapi, keseluruhan proses pemetaan partisipatif berbasis SIG ini masih membutuhkan koreksi dan perbaikan.
Sistem Informasi Geografi (SIG) sudah menjadi perangkat informatif untuk pengelolaan bencana dan mampu mencakup keseluruhan fase siklus pengelolaan bencana yaitu mitigasi, kesiapsiagaan, tanggap darurat, dan pemulihan asca bencana (Cutter, 2003). Namun, dari beberapa fase tersebut, SIG paling berperan pada saat tanggap darurat dan pemulihan bencana. Hal ini ditunjukkan oleh Gambar 3 yang menjelaskan hasil pemetaan partisipatif masyarakat Desa Pagar Jaya tentang jalur evakuasi tsunami yang telah diadopsi melalui perangkat SIG. Peta tersebut secara sederhana menggambarkan persebaran titik evakuasi akhir (TEA) dan sementara (TES), serta jalur evakuasi yang representatif digunakan ketika tanggap darurat bencana. Pembedaan fungsi TEA dan TES adalah pada persebaran jumlah penduduk desa yang cenderung mengelompok di sisi barat desa dan adanya lokasi yang representatif dimanfaatkan untuk evakuasi korban bencana tsunami. Beberapa titik yang digunakan oleh warga Desa Pagar Jaya antara lain pertigaan sekitar T. Hantu (TES 1); lapangan dekat panel surya Dusun Pagar Harapan (TES 2); serta Lapangan Balai Desa Pagar Jaya (TEA). Pemilihan lokasi evakuasi tersebut didasarkan atas pertimbangan luas area cukup lapang untuk didirikan tenda darurat, aksesibilitas yang relatif mudah dijangkau warga, serta elevasi yang lebih tinggi dibandingkan wilayah sekitar.

\section{Kesimpulan}

Berdasarkan hasil pengabdian yang telah diperoleh, dapat disimpulkan bahwa penerapan teknik pemetaan partisipatif untuk pemetaan sumber daya desa dengan melibatkan nara sumber yang berkompeten di lingkungan desa dapat melengkapi teknik pemetaan konvensional guna menghasilkan produk peta sumber daya desa yang lebih komprehensif. Berbagai informasi spasial yang tersimpan dalam mental map nara sumber dapat diterjemahkan dalam obyek spasial, termasuk informasi - informasi yang sulit diperoleh menggunakan teknik pemetaan konvensional, seperti misalnya titik kumpul. Pemetaan partisipatif juga dapat melengkapi atribut obyek dari hasil pemetaan konvensional, seperti pemisahan kelas jalan, informasi nama jalan, serta jenis dan nama fasilitas umum. Melihat besarnya manfaat strategis dari teknik pemetaan partisipatif dalam kegiatan survei dan pemetaan skala besar, setiap kegiatan pemetaan skala besar yang dilaksanakan organisasi 
pemerintah dan non pemerintah disarankan dapat mempertimbangkan penggunaan teknik ini disamping teknik pemetaan konvensional guna memperoleh hasil pemetaan yang lebih detil, akurat dan lengkap, baik secara tematik maupun geometrik.

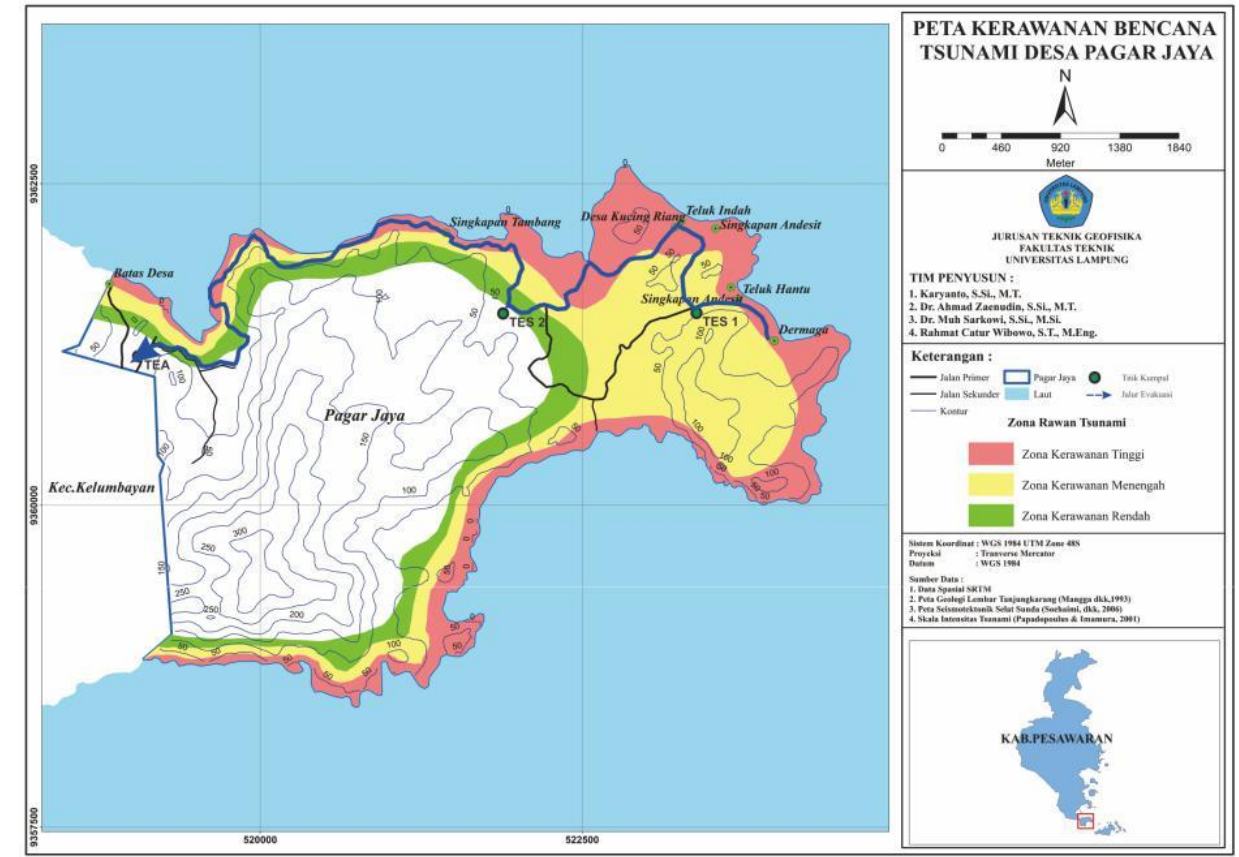

Gambar 3. Hasil pemetaan partisipatif masyarakat tentang jalur evakuasi tsunami yang telah diadopsi melalui perangkat SIG

\section{Daftar Pustaka}

BPS Pesawaran (2018) Kecamatan Punduh Pidada dalam Angka. BPS Kabupaten Pesawaran, Pesawaran.

Cadag, J.R.D. and J.C. Gaillard (2012) Integrating Knowledge and Actions in Disaster Risk Reduction: The Contribution of Participatory Mapping, Royal Geographical Society, Vol. 44 No. 1, pp. 100-109, 2012.

Cutter, SL 2003, GI Science, Disasters, and Emergency Management Transactions in GIS, 7, 439-446.

Dekens J 2007, Local knowledge for disaster preparedness: a literature review, International Centre for Integrated Mountain Development, Kathmandu.

Dowling, R.K., and Newsome, D. (2006) Geotourism: Sustainability, Impacts, and Management. Elsevier Butterworth-Heinemann. UK. ISBN:0750662158, 289.

Gaillard, J.C. (2010) Vulnerability, Capacity and Resilience: Perspectives for Climate and Development Policy. Journal of International Development. 22, 218-232.

Gaillard J C, Pangilinan MRM, Cadag J R, and Le Masson V. (2008) Living with increasing floods: insights from a rural Philippine community.
Disaster Prevention and Management, 17 38395.

Karyanto, Zaenudin, A., Sarkowi, M., dan Wibowo, R.C. (2018) Studi Pemetaan Potensi Geowisata Berbasis Drone Di Kecamatan Punduh Pidada untuk Meningkatkan Partisipasi Masyarakat Dalam Tata Kelola Pariwisata Berkelanjutan, Prosiding Pengabdian Kepada Masyarakat LPPM Unila, Bandar Lampung

Piccolella, A. (2013) Participatory mapping for adaptation to climate change: the case of Boe Boe, Solomon Islands. Knowledge Management for Development Journal. 9(1): 24-36.

Sinarta, I.N. (2013) Ancaman Tanah Longsor Sebagai Salah Satu Indikator Dalam Pembangunan Infrastruktur Berkelanjutan. Seminar Nasional Struktur Konsepsi \#1, Fakultas Teknik, Universitas Warmadewa, ISBN: 978-979-180455-4.

Spanu, V., Gaprindashvili, G. and McCall, M.K. (2015) Participatory Methods in the Georgian Caucasus: Understanding Vulnerability and Response to Debrisflow Hazards, International Journal of Geosciences, 6, 666-674.

Sutanto. (1986). Penginderaan Jauh Jilid I. Yogyakarta: Gadjah Mada University Press. 